\section{Original} Article

\begin{tabular}{|l|}
\hline Access this article online \\
\hline $\begin{array}{l}\text { Website: } \\
\text { www.ajobe.org }\end{array}$ \\
\hline DOI: \\
10.4103/1817-7417.86043 \\
\hline Quick Response Code: \\
\hline
\end{tabular}

Address for Correspondence: Prof. GJ (Deon) Rossouw, Ethics Institute of South Africa PO Box 11233, Hatfield 0028 Pretoria, South Africa

E-mail: deon.rossouw@ethicssa.org

\title{
The state of Business Ethics as field of teaching, training and research in Sub-Saharan Africa
}

\author{
GJ (Deon) Rossouw \\ Philosophy Department, University of Pretoria, South Africa \\ ABSTRACT
}

This article provides a comparative summary of the findings of the survey of Business Ethics as field of Teaching, Training and Research across the four sub-regions in Sub-Saharan Africa (Western Africa, Southern Africa, Eastern Africa and Francophone Africa). The article commences with a discussion on the terminology that is used to refer to Business and Economic Ethics in Sub-Saharan Africa. It then provides an overview of the prevalence and distribution of Business Ethics as field of Teaching, Training and Research in Sub-Saharan Africa that demonstrates the substantial growth in the field of Business Ethics since 2000 when an earlier survey was conducted. The focus areas in the field of Business Ethics are identified as well as the major themes that were found with regard to Teaching, Training and Research in Business Ethics. Also the major challenges that are foreseen in the field of Business Ethics over the next five year are discussed. Finally a number of concluding remarks are made that highlight unique features and challenges in the current state of Business Ethics in Sub-Saharan Africa.

Key words: Business ethics, Teaching, Training, Research, Sub-Saharan Africa

\section{INTRODUCTION}

In this concluding contribution to this special issue on the Sub-Sahara African survey of Business Ethics, a comparative summary of the findings across the four sub-regions (Western Africa, Southern Africa, Eastern Africa and Francophone Africa) will be presented. The article will commence with a discussion on the terminology that is used to refer to Business and Economic Ethics in Sub-Saharan Africa. Then an overview of the prevalence and distribution of Business Ethics as field of Teaching, Training and Research will follow. The focus areas in the field of Business Ethics are then discussed as well as the major themes that emerged with regard to Teaching, Training and Research in Business Ethics. Also the major challenges that are foreseen in the field of Business Ethics over the next five year are summarised. Finally a number of concluding remarks will be made that highlight unique features and challenges in the current state of Business Ethics in SubSaharan Africa.

\section{TERMINOLOGY}

The terminology that is most widely used across the Sub-Saharan Africa region in institutions of higher learning to refer to the field of Economic and Business Ethics is the term 'Business Ethics'. There is, however, some ambivalence to be detected in the fact that Business Ethics is used to refer to both Economic and Business Ethics. On the one hand the term 'business' is used in the broader sense of the word that also includes the 'economic' dimension within its scope of meaning. On the other hand there is an inherent tendency in the use of the term 'Business Ethics' to narrow its scope of meaning to ethics on the enterprise level. Some respondents indicated that they prefer the term 'enterprise ethics' to refer to the field of Economic and Business Ethics, whilst others narrowed it further down to 'managerial ethics'. Some other respondents narrowed it even still further down to the ethics of specific fields of management, such as 'marketing ethics' or 'procurement ethics'. Another indication of the tendency to narrow the scope of meaning of Business Ethics down to the enterprise level is evident from the close association that respondents made between Business Ethics and corporate governance on the enterprise level. This close association is particularly prevalent in Southern and Eastern Africa where the term 'Business Ethics' is often used in combination 
with the term 'corporate governance' in the names of modules in which Business Ethics is being taught. Also the term 'ethique des affairs' that is the most widely used term to refer to the field of Economic and Business Ethics in French speaking countries, conveys a similar narrowing down of the field to enterprise ethics.

Another peculiar aspect of the use of the term 'Business Ethics' across the Sub-Sahara African region is that its scope of meaning includes both the 'business' of the private sector and the 'business' of the public sector. Business Ethics is thus seen as closely related, and as an integral aspect of anti-corruption initiatives in the public sector. In Ethiopia, for example, respondents indicated that the term 'civic education' is an equivalent for the term 'Business Ethics'. This is due to the fact that the Ethiopian Government has a Federal Ethics and Anti-corruption Commission (FEAC) that is heavily involved in teaching and training on Ethics on both the secondary and tertiary education levels. There are two possible explanations for the fact that the term 'Business Ethics' is so easily extended from the private to the public sector across the Sub-Saharan Africa. The first reason for this phenomenon is that the state is still a major player in the economies of many states in Sub-Saharan Africa through state-owned enterprises. As a major player in business it thus makes perfect sense to include the public sector within the ambit of the meaning of the term 'Business Ethics'. The second reason is related to the corporate governance reform movement in Africa. A pertinent part of the corporate governance reform agenda in Sub-Saharan Africa is to curb corruption on the continent. There is a strong expectation that the improvement of ethical standards in both business and government will curb the spread of corruption on the continent. It is for this reason that the corporate governance reform movement often targets both the public and private sectors in its promotion of ethical standards.

As part of the investigation into the terminology used across the Sub-Sahara African region with regard to Business Ethics, respondents were asked what terminology they use in their mother tongue (if they are not first language English speakers) when they refer to the field of Economic and Business Ethics. In this respect two interesting trends were detected. In Afrikaans that is widely spoken in South Africa, the same ambivalence as discussed above occurred. The terms 'besigheidsetiek' or 'sake-etiek' were most widely used. Both terms can be directly translated into 'Business Ethics' thus again excluding any reference to economic ethics, but clearly implying it. However, the narrowing of the term Business Ethics to enterprise ethics, or specific aspects thereof, was also evident in terminology such as 'bestuursetiek' (directly translated as 'management ethics'), 'bemarkingsetiek' (directly translated as 'marketing ethics'), and 'aankope etiek' (directly translated as 'procurement ethics').
In the rest of Sub-Saharan Africa a different trend emerged. Respondents either indicated that they do not have a term in their mother tongue that is the equivalent of the term 'Business Ethics', or alternatively they tried to create an expression in their mother tongue that could serve as an equivalent for the term 'Business Ethics'. However, it soon became clear that there is no consensus amongst respondents sharing the same mother tongue on the appropriate terminology to be used to refer to Business Ethics. Examples of such creations in Tanzania were the expression: 'Maadili ya uchumi na biashara' (in Swahili language) and in Uganda the expression: 'Ebyobushubuzi hamwe nemitwarize y'obushubuzi' (in the Rukiga language). This phenomenon was clear in Western, Central \& Francophone, and Eastern Africa. However in all these regions there were well established terminology that expresses ethical obligations, duties and responsibilities in general, but not specifically in the domain of business. Such terminology that expresses general ethical obligations is firmly embedded in the religious and cultural contexts from which they originate.

The explanation for the two discrepant tendencies with regard to mother tongue terminology between Afrikaans and other African languages is to be found in the fact that mainly English and French are being used as languages of teaching and research at institutions of higher learning where Business Ethics as academic field has been introduced. The native languages are not used as languages of teaching and research and thus the academic terminology of the field of Economic and Business Ethics has not developed in these native languages. In the case of Afrikaans, however, the language is well established as language of training, teaching and research and consequently well established terminology with regard to the field of Economic and Business Ethics has emerged in Afrikaans over the last 25 years.

\section{PREVALENCE AND DISTRIBUTION OF BUSINESS ETHICS}

Although the distribution of expertise in Business Ethics in the Sub-Saharan Africa region is uneven and patchy there are some patterns to be discerned. Business Ethics as field of Training, Teaching and Research is clearly still an emerging field with the exception of South Africa where it has found its way into the mainstream of higher education. However, compared to the 2000 survey of Business Ethics in Africa it is clear that great strides have been made since then in the institutionalization of Business Ethics.

The two regions where Business Ethics as field of training, teaching and research is most prevalent are Southern and Eastern Africa. In South Africa Business Ethics is being taught at most Universities and Business Schools. At universities it is mostly offered by Philosophy and Accounting departments. At Business Schools experts in the field of 
Business Ethics are employed on a full or part-time basis for teaching and supervising postgraduate research. Five Centres with a specific (although not sole) focus on Business Ethics have also been established at four Universities. Various professional associations, like accounting, health care, human resource management, and engineering, are involved in Business Ethics training for their registered members. In the rest of Southern Africa courses with a clear Business Ethics dimension were only identified at the University of Botswana and at one university in Zimbabwe. Evidence was also found of Business Ethics related research in both Angola and Mozambique.

In Eastern Africa, Business Ethics as field of training, teaching and research has expanded significantly in the period under review (1995-2010) - particularly in Uganda, Kenya and Tanzania. It is clear that the lead in this regard has been taken by the younger and faith-based universities. In Uganda 10 universities do have Business Ethics offerings in their curricula, in Kenya it is found in 7 universities and in Tanzania 5 universities gave an indication of being involved in Business Ethics teaching. In Ethiopia 6 universities indicated that they are offering courses on "ethics and civic education" but these courses tend to have a more general anti-corruption and citizenship focus rather than an explicit focus on Business Ethics. Only one university in Ethiopia offers a dedicated course on Business Ethics. In Somalia web-searches indicated some activity regarding Business Ethics at 4 universities, but no further confirmation of the extent and focus areas of these activities could be found. Besides universities that offer courses on Business Ethics, a further 10 other institutions were identified in Eastern Africa that are involved in the field of Business Ethics. They are mostly professional associations (accounting and banking), national anticorruption agencies and organizations devoted to the promotion of good governance.

In Western Africa as well as in Francophone Africa activity in the field of Business Ethics is much sparser. In Western Africa activity in the field of Business Ethics is mostly concentrated in Nigeria, Ghana, and Cameroun, with scant activity reported in Benin Republic and Togo. Business Ethics is still an emerging field in Western Africa with once more the younger and faith-based universities taking the lead in introducing Business Ethics into the curricula. Although Business Ethics is not well established in this region, there are indications of strong advocacy related to Business Ethics and good governance that has the potential of stimulating training, teaching and research in the field of Economic and Business Ethics. The same can be said of the Francophone African region, where there are clear indications of strong advocacy for improved ethics and governance in the private and public sector, but very little evidence of teaching and training in the field of Business Ethics. Only in the Ivory Coast one university could be identified that offer a dedicated programme on Business Ethics on both undergraduate and postgraduate level. In Burundi Business Ethics is also taught on undergraduate level in only one university. Further evidence of teaching in the field of Business Ethics was also uncovered in Senegal, Rwanda and the Democratic Republic of Congo. However, there is more activity with regard to research in Business Ethics that most probably has some connection with the emerging advocacy for improved ethics and governance in this region.

Compared to the 2000 survey of Business Ethics in Africa, when activity in the academic field of Business was only detected in 4 countries in Sub-Saharan Africa, the current survey indicate that the number of countries involved in training, teaching and research in this field have since grown to at least 20 countries in this region. The Business Ethics Network of Africa (BEN-Africa) that was founded in 2000 most probably played a significant role in stimulating growth in the field of Business Ethics. The regions where BEN-Africa has been most active, viz. Southern and Eastern Africa are also the regions that reported the most activity in the field of Business Ethics.

\section{FOCUS AREAS IN BUSINESS ETHICS}

Comparing the areas of focus of both individuals and institutions across the four sub-regions in Sub-Saharan Africa, it is clear that there are a number of common focus areas that are being shared across the region. These shared areas of focus can be clustered into 6 themes, which are:

- Theoretical foundations of Business Ethics: Ethical theories, theories of the modern corporation, management theories, theoretical frameworks and concepts, and reflections on Economic and Business Ethics as field of study.

- Macro-economic and systemic challenges: Economic ethics, development ethics and poverty alleviation, globalization, and social and environmental sustainability.

- Corporate responsibility: Corporate moral agency, corporate citizenship, corporate obligations towards the socio-economic and natural environment.

- Ethical management and leadership: Corporate governance, ethics management, and the prevention of corruption and corporate malpractices.

- Ethical issues in business: Conflict of interests, HIV/ AIDS, health, safety, gender, marketing or cultural issues, etc.

- Professional ethics: The ethical responsibilities of specific professions.

The theme that is the most prominent across the four regions in Sub-Saharan Africa is the one on 'ethical management and leadership', where the sub-themes of corporate governance, ethics management and the prevention of corruption and corporate misconduct are the most popular areas of focus. 
It is, however, striking that in Francophone Africa there is a much stronger emphasis on economic and development ethics than in the other sub-regions. The other focus areas that are also particularly strong in this sub-region are corporate governance and the prevention of corruption. This combination of focus areas provides an explanation for the strong emphasis on advocacy for improved ethics and governance in the private and public sector that has been highlighted in the discussion above about the prevalence of Business Ethics in Francophone Africa.

Another striking feature is that only in South Africa are there indications of reflection on the development of the field of Business Ethics. This can be explained by the fact that the field of Business Ethics had its early development on the African continent in South Africa and has thus matured to a greater extent in South Africa than in other African countries. It is typical of the maturation process in any field of study to reflect on the development of the field as it grows and develops over time.

\section{THEMES IN TRAINING ON BUSINESS ETHICS}

Training on Business Ethics across the Sub-Saharan Africa region is offered mostly by universities (and more specifically by centres for ethics with a focus on Business Ethics), professional organizations (such as for accountants or bankers), and anti-corruption agencies. The range of topics covered in training are much narrower than the focus areas discussed in the previous section. There are three main themes that dominate in training programmes. They are:

- Ethics management: Building ethical organizations; developing and implementing codes of ethics; ethics management structures; identifying and mitigating ethics risk; reporting on ethics performance; and ethical decision-making.

- Corporate governance: The ethical dimension of corporate governance, ethics governance structures; the governance of corporate ethics, and ethical leadership and culture.

- Prevention of corruption and corporate malpractices: Prevention, detection and dealing with corruption and fraud in organisations.

It is thus clear that the main topics that are covered in training cluster around the theme of ethical management and leadership that was identified above as one of the six areas of focus. This is not surprising since training programmes are much more focussed on the practice of management and consequently these topics that deal with the practical side of governing and managing ethics in organizations form the core focus of training programmes.

Two minor themes that are covered in some of the training programmes are professional ethics and sustainability. Especially in Southern and Eastern Africa professional ethics training is offered by professional associations for accountants, directors and bankers. In Southern Africa and Francophone Africa the topic of sustainability is appearing in some programs. This focus on sustainability fits in well with the emphasis on macro-economic and systemic ethics in Francophone Africa, as well as with the strong emphasis on triple bottom line reporting in the corporate governance regime in South Africa.

\section{THEMES IN TEACHING ON BUSINESS ETHICS}

A total number of 145 modules in which Business Ethics is being taught have been identified across the Sub-Saharan Africa region. These modules were more or less equally divided between the undergraduate $(74$ modules) and postgraduate levels (71 modules).

There are four broad themes that are generally to be found in modules on Business Ethics that are taught across the Sub-Saharan Africa region. These four themes are:

- Theoretical foundations of Business Ethics: Ethical theories, theories of the modern corporation, management theories, theoretical frameworks and concepts.

- Macro-economic and systemic challenges: Economic ethics, development ethics and poverty alleviation, globalization and social and environmental sustainability.

- Corporate responsibility: Corporate moral agency, corporate citizenship, corporate obligations towards the socio-economic and natural environment.

- Ethical management and leadership: Corporate governance, ethics management and the prevention of corruption and corporate malpractices.

The theoretical basis of teaching is clearly reflected in this combination of themes. Unlike the themes that emerged in training programmes, where the emphasis is much more on the practical side of governing and managing ethics in organization, the emphasis in formal educational curricula are much more on conceptual and theoretical frameworks that can assist in making sense of the ethical dimension of business. Inevitably, since universities are also involved in professional and vocational formation, there is also an emphasis on the practical side of governing and managing ethics in organizations, but this emphasis is countered by the more theoretical aspects of ethical theories and concepts, macro-economic theories and frameworks, and reflection on the role and responsibilities of business in society.

In a comparison across the four sub-regions in Sub-Saharan Africa, it is striking that there is much more of an issuebased approach to teaching Business Ethics in South Africa. Specific business ethical issues that are pertinent to the South African context, such as HIV/AIDS, whistle-blowing or Black Economic Empowerment are integrated into the Business Ethics curriculum. Once more, as in the case of training programmes, there is also more emphasis on 
professional ethics in the Southern and Eastern African regions.

The only noteworthy difference to be detected between the teaching of Business Ethics on the undergraduate versus the postgraduate level is that there is less focus on the postgraduate level on the theoretical foundations of Business Ethics. On postgraduate level the focus tend to be more on the macro-economic, corporate responsibility and ethics management dimensions of Business Ethics.

A pattern that emerged with regard to the issue of whether courses in Business Ethics are elective or compulsory, is that that there are very few purely elective courses on offer. What does occur quite often, however, is that while a course is compulsory for some students, it is also offered as an elective for students in other programmes. This practice makes sense within the context of African universities where academics tend to have heavy teaching obligations, and consequently often do not have the luxury of offering purely elective modules.

\section{THEMES IN BUSINESS ETHICS RESEARCH}

A total of 218 research publications were identified across the Sub-Saharan Africa region and analyzed to determine the main themes that have emerged in research in the region. From this analysis it is clear that three main focus areas of research are found across this region. These focus areas are:

- Macro-economic and systemic challenges: Economic ethics, development ethics and poverty alleviation, globalization and social and environmental sustainability.

- Ethical management and leadership: Corporate governance, ethics management and the prevention of corruption and corporate malpractices.

- Theoretical foundations of Business Ethics: Ethical theories, theories of the modern corporation, management theories, theoretical frameworks and concepts, and reflections on Economic and Business Ethics as field of study.

It is striking that the macro-economic and systemic dimension is so prominent in research publications. The macro-economic and systemic dimension includes macroeconomic policies, economic development policies, poverty alleviation and economic globalization. What is further noteworthy is that this emphasis on the macro-economic and systemic dimension is particularly strong in the two sub-regions where Business Ethics as field of training and teaching are least developed, viz. Western and Francophone Africa. Two possible explanations can be offered for this phenomenon. The first is that the main cause of problems in the domain of Economic and Business Ethics is perceived to be structural, rather than functional. The second might have to do with the strong role of faith-based institutions (universities and NGOs) in the production of research in Western and Francophone Africa. Theological approaches to the field of Economic and Business Ethics tend to focus on the macro-economic and systemic level, rather than on the meso- and micro-economic level.

Within the Southern Africa sub-region, and more specifically in South Africa, 'corporate responsibility' (i.e. corporate moral agency, corporate citizenship, corporate obligations towards the socio-economic and natural environment) is also a prominent focus area in research. However this area of focus is relatively weak in the rest of the Sub-Saharan region and can therefore not be regarded as a focus area for the region as a whole. This discrepancy probably can be explained by the relatively well developed corporate sector in South Africa compared to the less developed corporate sector in the rest of the Sub-Saharan Africa region.

Two other foci of research across the Sub-Saharan Africa region are 'ethical issues in business' (such as HIV/ AIDS, gender, cultural clashes, conflict or interests) and 'professional ethics' (such as ethics for accountants, bankers, public servants). However in terms of the quantity of research focused on these areas, they enjoy much less prominence than the other focus areas of research outlined above.

Major business ethical issues over next five years Respondents in this survey were requested to indicate what they foresee as the most important challenges in the field of Business Ethics over the next five years. Although responses were varied - as could be expected - some clear patterns emerged in the analysis of the challenges that are foreseen. The following four categories of challenges in the field of Business Ethics have been identified:

- Global Fairness: The challenge around which most of the responses clustered were the one that indicated that much work will have to be done in the field of Business Ethics in order to develop an economic system that is fair on a global scale. Specific issues with regard to this challenge that were identified are:

- Global standards of economic and business conduct;

- Respect for Human Rights;

- Ethical capitalism;

- Fairness in international trade;

- Global poverty alleviation and eradication; and

- Regulation of international business and banking transactions.

- Sustainability: There was also a substantial consensus amongst respondents that sustainable economic development and sustainable business practices will be high on the Business Ethics agenda over the next five years. Especially the impact of business on the natural environment has been emphasized. 
- Business and Society: The relationship between business and society as well as the redefinition of the role and responsibility of business towards society are regarded as issues that will remain prominent on the Business Ethics agenda.

- Organizational ethics management: Also the governance and management of ethics in organizations are seen as a challenge that will remain pertinent over the next five years. In this regard special emphasis was placed on the development of ethics management structures and processes to prevent corruption and fraud in organizations. The governance of corporate ethics is deemed to remain an important issue, while the cultivation of ethical corporate culture is tipped to become a more prominent challenge.

\section{CONCLUSIONS}

From the above overview of findings it is clear that there has been substantial growth in activity in Economic and Business Ethics as field of Training, Teaching and Research over the period from 1995-2010. The first attempt at studying Business Ethics as field of study on the African continent in 1995 did not provide a reliable baseline against which the current state of Business Ethics in Sub-Saharan Africa can be assessed. However, the 1999 survey by Barkhuizen did provide such a baseline. Compared to the 1999 survey, which registered activity in the field of Business Ethics in only 4 Sub-Saharan countries, the current survey found evidence of activity in the field of Business Ethics training, teaching and research in at least 20 countries in this region.

The distribution of activities in the field of Business Ethics in Sub-Saharan African is still quite skewed. The sub-region where most activity is occurring is Southern Africa, but these activities are almost exclusively concentrated in one country in this sub-region, viz. South Africa. The region were activity is best dispersed across the region is Eastern Africa, where activities were recorded in five countries of that sub-region. In Western Africa and Francophone Africa activity in the field of Business Ethics remains rather sparse with most efforts focused on advocacy and research rather than on training and teaching.

The survey has demonstrated the important role that formal networks play in the field of Business Ethics. In those regions where there are existing networks to link experts in the field of Business Ethics, the survey process had been much easier and more effective compared to regions where there were little or almost no networks available to link experts in the field. It also seems that the existence of an effective network to link experts in the field also has a positive impact on the growth of the field of Business Ethics. The Business Ethics network of Africa (BEN-Africa), which was founded in 2000 concentrated most of its activities on Southern and Eastern Africa, which also turned out to be the sub-regions where most activity in the field of Business Ethics are currently registered.

A further striking feature of the survey is that the introduction of Business Ethics, specifically as field of training and teaching, is often initiated by younger - often faith-based - tertiary educational institutions. The reform of teaching curricula in these younger institutions seems to be a less onerous process compared to curricular reform in the older well-established universities. In this respect Business Ethics is no exception as field of study, but rather just another manifestation of the fact that younger institutions often find it easier to introduce innovation than older institutions with long traditions. This does not imply at all that Business Ethics cannot be introduced in older mainstream universities. The case of South Africa, where Business Ethics now forms part of the curricula of most mainstream universities, demonstrates that it is indeed possible to mainstream Business Ethics into the curricula of well established universities. It just might take longer to do so in older educational institutions.

The prevalence of corruption and corporate misconduct in Sub-Saharan Africa seems to have had a definitive influence on how the field of Business Ethics has been shaped in this region. The analysis of the areas of focus of expertise as well as the areas of focus in training programmes indicated that the main focus in the field of Business Ethics is on ethical management and leadership. This indicates a concern to find practical solutions to deal with corruption and corporate misconduct. Even in the Western Africa and Francophone Africa sub-regions, where training and teaching in the field of Business Ethics is not well developed, it seems that advocacy to turn the tide of corruption and corporate misconduct is the dynamo that drives research in Economic and Business Ethics.

The strong emphasis on the prevention of corruption and corporate misconduct had the effect of skewing the field of Business Ethics towards the meso - and micro-economic levels, with the result that the macro - economic dimension of Business Ethics has been somewhat neglected. This neglect does seem to be recognized by experts in the Sub-Saharan Africa region, as this is the area that most of them identified as the area in the field of Business Ethics that should become a priority over the next five years.

\section{REFERENCES}

Barkhuysen, B. 1999. A survey of the current status of Business Ethics as an academic field in Africa. MA dissertation, Johannesburg: Rand Afrikaans University.

Ike, O. 2011. Business Ethics as a Field of Teaching Training and Research in West Africa. African Journal of Business Ethics, 5(2): 89-95.

Kagabo, L. 2011. Business Ethics as field of Training, Teaching and Research in Francophone Africa. African Journal of Business Ethics, 5(2): 74-80.

Mawa, M. \& Adams, J. 2011. Business Ethics as field of Teaching, 
Training and Research in East Africa. African Journal of Business Ethics, 5(2): 66-73.

Smurthwaite, M. 2011. Business Ethics as Field of Training, Teaching and Research in Southern Africa. African Journal of Business Ethics, $5(2): 81-88$.
How to cite this article: (Deon) Rossouw GL. The state of Business Ethics as field of teaching, training and research in Sub-Saharan Africa. Afr J Bus Ethics 2011;5:96-102.

Source of Support: Nil, Conflict of Interest: None declared

\section{AUTHOR}

Prof. Deon Rossouw is CEO of the Ethics Institute of South Africa and Extraordinary Professor in Philosophy at the University of Pretoria. He was the Founding President of the Business Ethics Network of Africa (BEN-Africa) and a former President of the International Society for Business Economics and Ethics (ISBEE). He is a member of the Sustainability Committee of the Third King Report on Corporate Governance for South Africa. He was responsible for initiating and coordinating the Global Survey of Business Ethics as field of Teaching, Training and Research while he served as Programme Director for Business Ethics at Globethics.net in Geneva during 2008/9.

Announcement

\section{iPhone App}

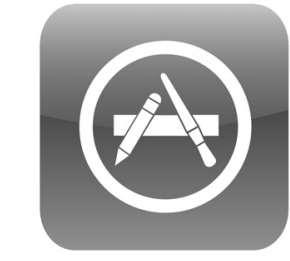

A free application to browse and search the journal's content is now available for iPhone/iPad. The application provides "Table of Contents" of the latest issues, which are stored on the device for future offline browsing. Internet connection is required to access the back issues and search facility. The application is Compatible with iPhone, iPod touch, and iPad and Requires iOS 3.1 or later. The application can be downloaded from http:// itunes.apple.com/us/app/medknow-journals/id458064375? ls $=1 \& \mathrm{mt}=8$. For suggestions and comments do write back to us. 
Reproduced with permission of the copyright owner. Further reproduction prohibited without permission. 